\title{
Silikon Protez Kullanılarak Rekonstrüktif Meme Cerrahisi Uygulanmış Hastada Minimal İnvaziv Sinüs Venozus Defekti Onarımı
}

\author{
Didem Melis Öztaş ${ }^{1} \odot$, Doğan Yetüt ${ }^{2} \odot$, Salih Duman ${ }^{3} \odot$, Hayri Ömer Berköz ${ }^{4} \odot$, \\ Ömer Ali Sayın²®, Murat Uğurlucan ${ }^{5} \odot$, Ufuk Alpagut ${ }^{2} \oplus$
}

\begin{abstract}
'Bağcılar Eğitim Araştırma Hastanesi, Kalp ve Damar Cerrahisi Kliniği İstanbul, Türkiye 2̇stanbul Üniversitesi İstanbul Tip Fakültesi, Kalp ve Damar Cerrahisi Anabilim Dalı, İstanbul, Türkiye

${ }^{3}$ Istanbul Üniversitesi İstanbul Tıp Fakültesi, Göğüs Cerrahisi Anabilim Dalı, Istanbul, Türkiye

${ }^{4}$ Istanbul Üniversitesi İstanbul Tıp Fakültesi, Plastik ve Rekonstrüktif Cerrahisi Anabilim Dalı, Istanbul, Türkiye

${ }^{5}$ Medipol Üniversitesi Tıp Fakültesi, Kalp ve Damar Cerrahisi Anabilm Dalı, İstanbul, Türkiye
\end{abstract}

Didem Melis Öztaş, 0p. Dr. Doğan Yetüt, Dr.

Salih Duman, Op. Dr.

Hayri Ömer Berköz, Op. Dr.

Ömer Ali Sayın, Doç. Dr.

Murat Uğurlucan, Doç. Dr.

Ufuk Alpagut, Prof. Dr.

İletişim:

0p. Dr. Didem Melis Öztaş

Bağcılar Eğitim Araştırma Hastanesi, Kalp ve

Damar Cerrahisi Kliniği İstanbul, Türkiye

Tel: +905535460107

E-Posta: didemmelisoztas@gmail.com

Gönderilme Tarihi : 25 Ekim 2017

Revizyon Tarihi : 06 Aralık 2017

Kabul Tarihi : : 10 Aralık 2017

\section{ÖZET}

Atriyal septal defekt erişkinde en sık rastlanan doğumsal kalp anomalilerinden biridir. Minimal invaziv cerrahi tekniklerdeki gelişmeler, seçilmiş uygun vakaların bu yöntemle daha yaygın olarak tedavi edilmesini artırmıştır. Sağ anterior torakotomi ile minimal invaziv olarak atriyal septal defekt onarımı güvenilir sonuçları, yüksek hasta memnuniyeti nedeniyle özellikle genç bayan hastalarda ilk sıralarda tercih edilecek yöntemlerden biridir.

Biz bu yazıda yaklaşık 3 yıl önce silikon meme protezi ameliyatı olan hastada uyguladığımız minimal invaziv teknik ile sinüs venozus defekti onarımını anlatmaktayız. Mevcut kompleks atrial septal defekt ve cerrahi alanda silikon meme protezi bulunmasına rağmen sağ anterolateral mini torakotomi yaklaşımı sayesinde uygulanan tedavi başarilı ve kozmetik olarak sorunsuz olmuştur.

Anahtar sözcükler: Atriyal septal defekt, sinüs venozus defekti, meme rekonstrüksiyonu, minimal invaziv cerrahi

\section{MINIMALLY INVASIVE SINUS VENOSUS DEFECT REPAIR IN A PATIENT WITH SILICONE BREAST PROSTHESIS}

\section{ABSTRACT}

Atrial septal defect is one of the most common congenital cardiac anomalies in adulthood. Advances in minimally invasive surgical approaches result in an increased use of these techniques in selected patients. Atrial septal defect closure with minimal invasive surgery through right anterior thoracotomy is one of the first chosen treatment methods with reliable results and high patient satisfaction especially in young ladies.

In this paper, we present the repair of sinus venosus defect with minimal invasive methods in a patient whom underwent breast reconstruction using a silicone prosthesis three years ago. The operation through right anterolateral minithoracotomy approach was successful and cosmetically uneventful even in the presence of a complex atrial septal defect and the silicone breast prosthesis in the surgical area.

Keywords: Atrial septal defect, sinus venosus defect, breast reconstruction, minimally invasive surgery triyal septal defekt (ASD) Rokitansky tarafından ilk kez 1875'te tarif edilmiştir (1). Hastalar sıklıkla asemptomatik olup, rastlantısal olarak tanı alsalar da; malformasyon düzeltilmediği takdirde bu defektler uzun dönemde önemli mortalite ve morbiditeye sebebiyet verebilir (2). Hastalığın günümüzde halen standart tedavisi median sternotomi insizyonu ile kardiyopulmoner bypass kullanılarak ASD'nin primer ya da yama ile kapatılması şeklindedir. 
Gelişen anestezi, cerrahi ve teknoloji ile birlikte kardiyovasküler cerrahi girişimlerde de kozmetik sonuçlar ve hasta memnuniyeti üzerinde önemle durulmaktadır. Minimal invaviz yöntemlerin kozmetik sonuçları yanında, kısa yoğun bakım ve hastanede kalış süresi, daha az kan ve kan ürünü gereksinimi, daha az ağrı, kısa sürede normal yaşama dönüş gibi pek çok avantajı mevcuttur. $\mathrm{Bu}$ da son yıllarda minimal invaziv tedavilerin uygun, seçilmiş vakalarda artarak kullanılır hale gelmesini sağlamıştır (3).

Silikon meme protezleri 1960 'lı yıllarda kullanıma girmiş ve modern meme rekonstrüksiyonu bu tarihten itibaren hızla ilerlemiştir (4). Özellikle mastektomi geçirmiş hastalar doku genişletici implant ile rekonstrüksiyona adaydır. Ancak meme rekonstrüksiyonunun gelişmesiyle birlikte estetik alanda da silikon meme protezlerinin kullanımı $\operatorname{artmıştır~(5).~}$

Yazımızda estetik amaçlı silikon meme protezi implantasyonu yapılmış hastada kompleks ASD'nin minimal invaviz yöntemlerle tedavisini sunmaktayız. Bu süreçte hastanın bilgilendirilmiş onamı alınmıştır.

\section{Vaka sunumu}

Hastamız 30 yaşında bayandı. Her hangi bir şikayeti yoktu. Varis nedeniyle başvurduğu merkezde yapılan fizik muayenede kalbinde üfürüm duyulması üzerine kontrol amaçlı yapılan ekokardiyografide sağ kalp boşluklarında genişleme, pulmoner hipertansiyon (sistolik pulmoner arter basıncı $45 \mathrm{mmHg}$ ), sinüs venosus tipi ASD saptanmıştı. Sağ inferior pulmoner ven defekt bölgesine açlırken, süperior pulmoner venin açılım lokalizasyonundan emin olunamamış ve kardiak bilgisayarlı tomografi ile değerlendirmesi yapılarak sağ üst pulmoner venin süperior vena kavaya açıldığı görülmüştü (Şekil 1a, 1b). Tedavi amacıyla kliniğimize baş vuran hastanın hikayesinde 6 yıl önce sezeryan doğum ve 3 yı önce kozmetik amaçlı silikon meme protezi operasyonu vardı. Soy geçmişinde bir özellik saptanmadı. Fizik muayenesi normaldi. Kardiak oskültasyonda mid sistolik üfürüm ile birlikte güçlü P2 ve ikinci kalp sesinde çiftleşme duyulmaktaydı.

Hastaya uygulanabilecek cerrahi tedavi yöntemleri, avantajları, dezavantajları anlatıldı. Hastanın ön plandaki kozmetik kaygıları da göz önüne alınarak minimal invaziv yöntemler ile sinüs venozus defekti tamiri operasyonu yapılmasına karar verildi. Mevcut seçenekler ve hastanın göğüs yapısı göz önünde bulundurulduğunda operasyonun sağ anterolateral torakotomi ile yapılması planlandı. Cerrahi sahada silikon meme protezi bulunması nedeniyle plastik ve rekonstrüktif cerrahi biriminden yardım alınmasına karar verildi.

\section{Cerrahi teknik}

Genel anestezi altında çift lümenli endobronşiyal tüp ile entübe edilen hasta 45 derece açıyla ön oblik pozisyonda ameliyat masasına alındı. Meme protezi insizyonunun üzerinden yapılan kesi ile proteze ulaşıldı. Protezin cerrahi alanda kalması üzerine plastik ve rekonstrüktif cerrahi ekibi tarafından silikon meme protezi çıkarıldı. Steril bir şekilde muhafaza edildi. Sağ akciğer selektif olarak söndürüldü. Dördüncü interkostal aralıktan toraks boşluğuna
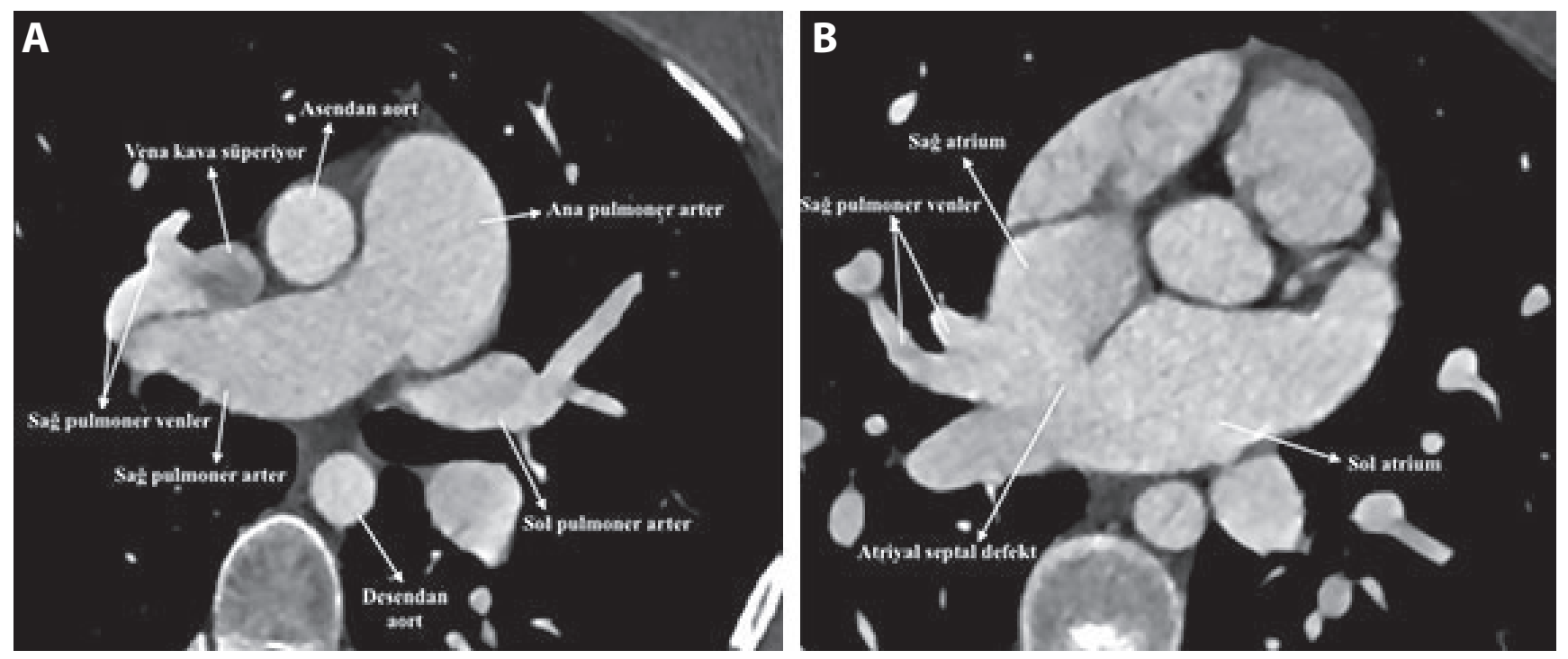

Şekil 1 A-B. Sağ üst pulmoner venlerin süperior vena kavaya açılığını gösteren kardiak bilgisayarlı tomografi görüntüsü. 
girildi. Perikard frenik sinirin anteriorundan açıldı. Cerrahi sahaya devamlı olarak karbondioksit üflendi. Sağ üst pulmoner ven süperior vena kavaya dökülmekteydi. Sağ alt pulmoner ven kavoatrial bileşkeye drene olmaktaydı (Şekil 2a). Aortik, inferior vena kava ve yüksek süperior vena kava kanülasyonlarıni takiben kardiyopulmoner bypass başlatıldı. Hipotermi uygulanmadı. Antegrad izotermik kan kardiyoplejisi ile kardiak arrest sağlandıktan sonra sağ atriotomi yapıldı. İnsizyon süperior vena kavanın anterioru boyunca uzatıldı. Defekt ve sağ pulmoner venlerin defekt ile ilişkisi görüldü (Şekil 2b). Sağ pulmoner venler sol atirumda kalacak şekilde, taze perikard, superior vena kava içinden başlayarak, geniş bir şekilde sağ atriumdaki defektin inferior ucuna dek sütüre edilerek sinüs venozus defekti uygun şekilde kapatıldı (Şekil 3). Vena kava superiorun insize edilen anterior bölgesi taze perikard yama ile genişletildi ve sağ atriotomi kapatıldı (Şekil 4). Hava tahliyesi ve dekanülasyon sonrası torakotomi ve kaslar anatomiye uygun olarak kapatıldı. Midaksillar hattan 1 adet toraks dreni yerleştirildi. Toplam myokard iskemi süresi 47 dakika, kardiyopulmoner bypass süresi 64 dakika idi. Toraks boşluğu kapatıldıktan sonra hasta plastik ve rekonstrüktif cerrahi ekibine devredildi. Çıkarılan damla silikon meme protezi eski lojuna sol meme ile simetrik
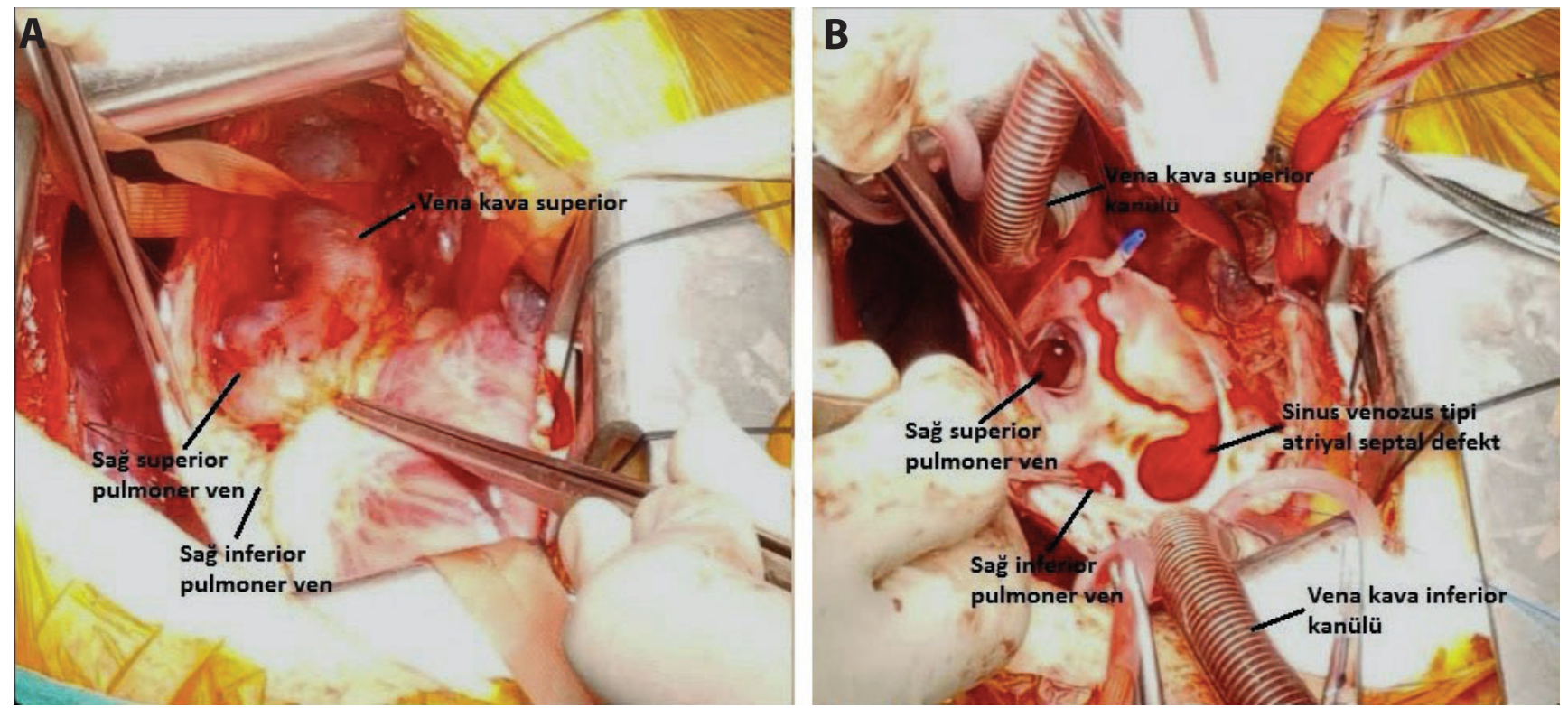

Şekil 2 A-B. Peroperatif görüntüde sinüs venosus tipi ASD ve sağ atriuma dökülen sağ pulmoner venler görülmektedir.

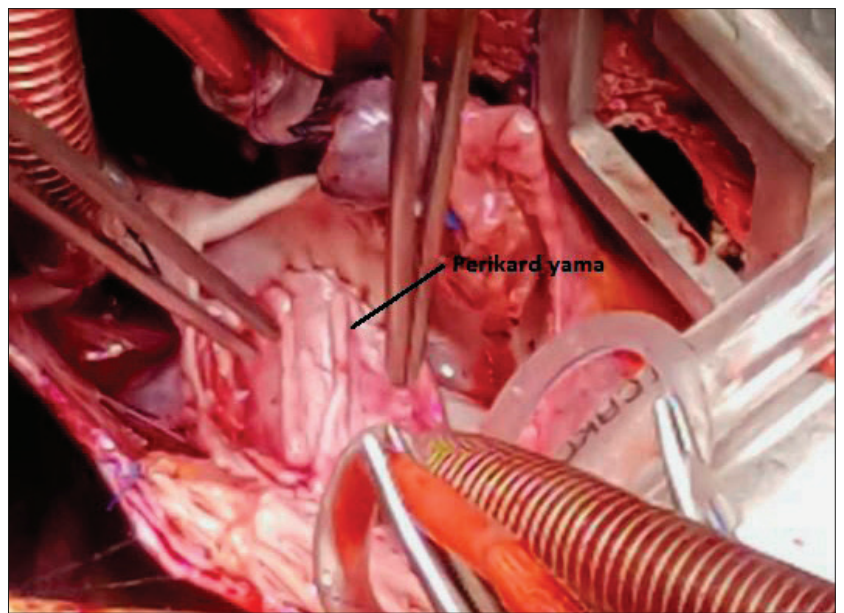

Şekil 3. Atriyal septal defekt kapatmada kullanılan perikard yama. Sağ pulmoner venlerin tümünün sol atriuma açılmasını sağlamak üzere superior vena kava içinden başlayarak inferiorda defektin alt rimine uzanacak şekilde genişçe yerleştirilmiştir.

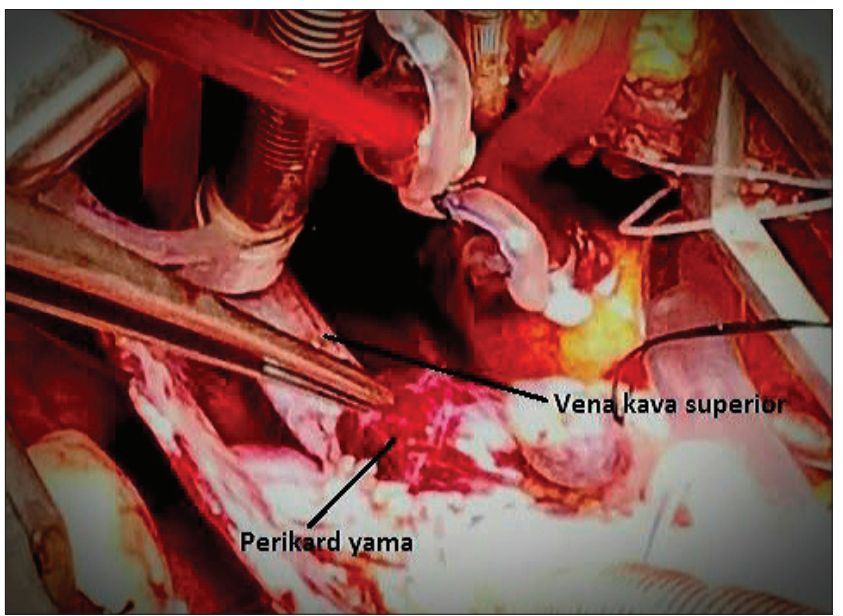

Şekil 4. Vena Kava Superior'u genişletmek amacıyla kullanılan perikard yama görülmektedir. 
olacak şekilde yerleştirildi (Şekil 5,6). Ameliyat sonrası ekstübe edilen hasta yoğun bakım ünitesine alındı ve burada 1 gün kaldıktan ve serviste 4 gün takip edildikten sonra postoperatif 5. günde taburcu edildi. Hastaya postoperatif dönemde plastik ve rekonstrüktif cerrahi biriminin de önerisi ile skar oluşumunu azaltmak amacıyla Extractum Cepea, Heparin ve Allantoin adlı maddeleri içeren jel (Contractubex', MERZ medikal, Almanya) reçete edildi. Kozmetik sonuçtan memnun olan hasta yaklaşık 6 aydır sorunsuz olarak takip edilmektedir.

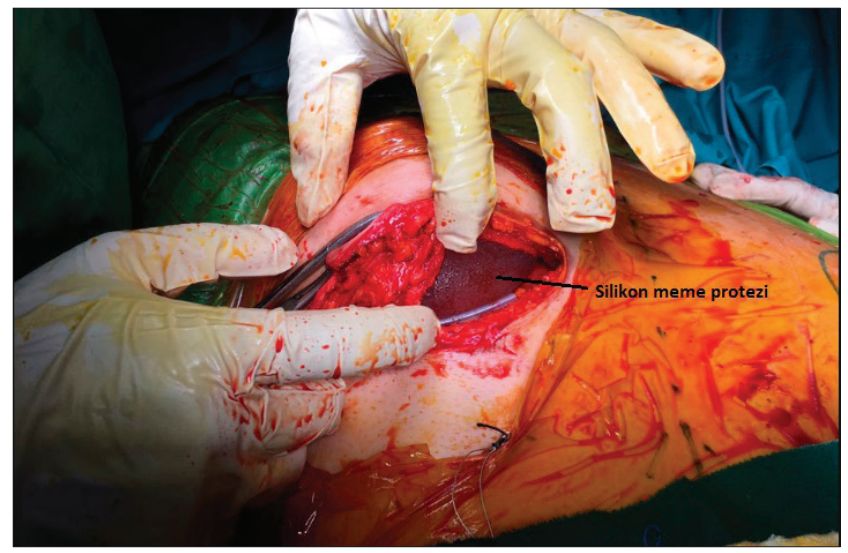

Şekil 5. Eski lojuna reimplante edilen silikon meme protezinin peroperatif görüntüsü.

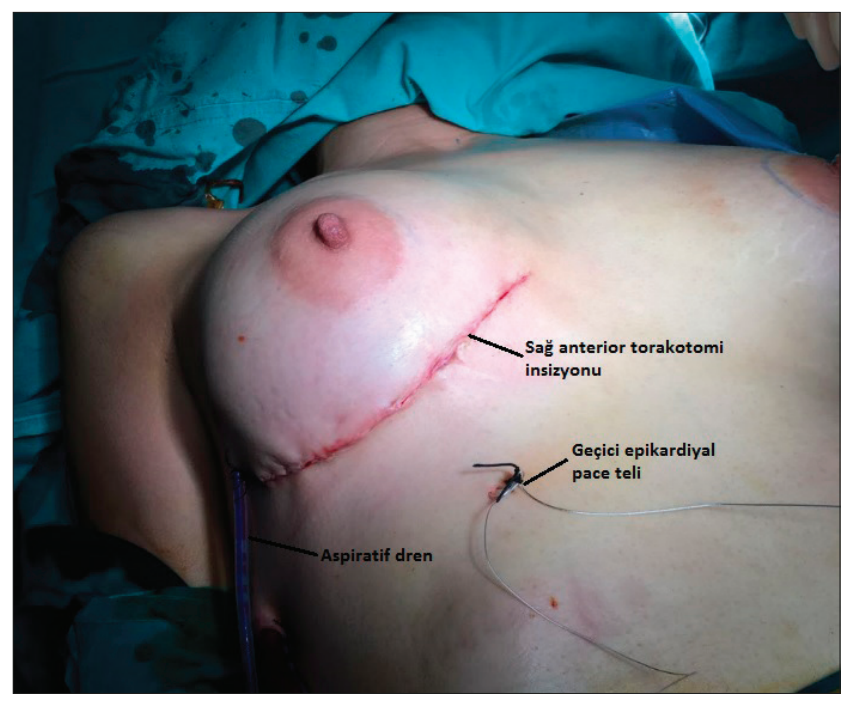

Şekil 6. Postoperatif görüntü.

\section{Tartışma}

Atrial septal defekt erişkinlerde en sık rastlanan doğumsal kalp anomalilerinden biridir. Çoğunluğunu sekundum ASD'ler oluşturmaktadır. Cerrahi olarak büyük oranda atriyal septum merkezinde yerleşmekle birlikte, yaklaşık \%6'sında süperior ya da inferior vena kavaya komşu sinüs venozus tip ASD görülür (6).
Tedavide çeşitli yaklaşımlar bulunmaktadır. Standart median sternotomi, lateral torakotomi, anterior torakotomi ve parsiyel sternotomi uygulanan tekniklerdendir. Günümüzde minimal invaziv cerrahi yaklaşımların önem kazanmasıyla video destekli mini torakotomi, robotik cerrahi gibi tamamen torakoskopik metotlar da uygulanmaktadır $(7,8)$. Bunların dışında uygun vakalarda perkütan yaklaşımlar da tercih edilmektedir.

Median sternotomi, cerrahi sahaya yaklaşımı kolaylaştırmaktadır. Minimal invaziv kardiyak cerrahi ise hastalar açısından daha konforlu bir metot olması, ağrıyı azaltması, hastanede kalış süresini kısaltması ve kozmetik açıdan daha kullanışlı olması nedeniyle son zamanlarda sıklıkla tercih edilen bir yöntem olmuştur $(9,10)$. Bununla birlikte minimal invaziv kardiyak cerrahinin sınırlı cerrahi saha ve buna bağlı teknik zorlukları bulunmaktadır. Sağ anterior torakotomi, sağ atriyuma kolay yaklaşım sağlaması nedeniyle kullanışıı bir teknik olup, insizyon cerrahi operasyon için gerekli olacak kadar minimize edilebilir (11).

Sağ anterior torakotomi ve standart median sternotomi ile opere olan hastalar karşılaştıııldığında mortalite ve morbidite açısından belirgin bir fark gözlenmemiştir (11). Bunun yanı sıra kozmetik sonuçları, hastanede kalış süresini kısaltması ve hasta konforu açısından sağ anterior torakotomi özellikle genç bayan hastalarda ilk sıralarda tercih edilecek yöntemlerden biridir (12).

Günümüzde rekonstrüktif işlemlerin giderek arttığı göz önüne alındığında silikon meme protez cerrahisi özellikle mastektomi yapılan hastalarda geniş kullanım alanı bulmaktadır (5). Uyguladığımız teknik ile bu hasta popülasyonunda da sağ anterior torakotomi ile minimal invaziv cerrahinin kullanım alanı bulacağı düşünülmektedir.

Bizim hastamız tedavi yöntemleri anlatıldığında kozmetik yönden ve hasta konforu açısından minimal invaziv yöntemle ameliyat olmak istediğini belirtti. Silikon meme protezi olan hastanın yapılacak sağ anterior torakotomi insizyonu sırasında protezin cerrahi alanda kalması nedeniyle operasyonun plastik ve rekonstrüktif cerrahi birimi desteği ile yapılmasına karar verildi. İnsizyonumuz protez cerrahisi için önceden yapılmış kesi bir miktar büyütülerek yapıldığı için ek skar dokusu oluşumu minimalize edilmiş oldu. Ayrıca bu kesi sayesinde kardiyopulmoner bypass için juguler ve femoral kanülasyona gereksinim duyulmadı ve standanrt aortik ve bikaval kanülasyonlar ile operasyon gerçekleştirildi. Bu da hastaya ek insizyon yapılmasını engellemiş ayrıca kardiyopulmoner bypassın 
daha güvenli uygulanmasını sağlamıştır. Hastanın silikon meme protezinin olması anterior torakotomi yapılmasını engelleyen bir faktör olarak düşünülmeyip, postoperatif herhangi bir kozmetik sorun yaşanmamıştır. Ek olarak skar gelişimini engelleyici ajanlar hastamıza reçete edilerek oluşacak nedbe dokusunun sınırlanması amaçlanmıştır.

İlerleyen teknoloji kalp cerrahisi geçirecek hastalara yapılacak insizyonların daha da küçük olmasına olanak vermektedir. Örneğin robotik kalp cerrahisi ya da video destekli torakoskopik cerrahi hastalar üzerinde neredeyse fark edilemeyecek kadar küçük kesi skarlarının oluşmasını sağlamaktadır (8). Hastamızda daha kozmetik olan bu yöntemleri tercih edemememizin en önemli sebebi trokanter girişlerinin hastanın meme protezine zarar verebilme ihtimalidir (12). Ek olarak kliniğimizde robot mevcut değildir.

\section{Kaynaklar}

1. Murphy JG, Gersh BJ, McGoon MD, Mair DD, Porter CJ, Ilstrup DM, et al. Long-term outcome after sugical repair of isolated atrial septal defect: follow-up at 27 to 32 years. N Engl J Med 1990;323:1645-50. [CrossRef]

2. Erentuğ V, Sareyüpoğlu B, Göksedef D, Kırali K, Güler M, Ipek G, et al. Closure of Atrial Septal Defects with Anterior Thoracotomy in Female Patients. Turkish J Thorac Cardiovasc Surg 2005;13:99-102. Erişim: http://tgkdc.dergisi.org/uploads/pdf/pdf_TGKDC_881.pdf

3. Yoshimura N, Yamaguchi M, Oshima Y, Oka S, Ootaki Y, Yoshida M. Repair of atrial septal defect through a right posterolateral thoracotomy: a cosmetic approach for female patients. Ann Thorac Surg 2001;72:2103-5. [CrossRef]

4. Radovan C. Breast reconstruction after mastectomy using the temporary expander. Plast Reconstr Surg 1982;69:195-206. [CrossRef]

5. Serel S, Şen Z, Kaya B, Emiroğlu M, Zeki C. İmplantlar ve doku genişleticiler ile meme rekonstrüksiyon. Ankara Üniv Tıp Fak Derg 2004;57:167-73.

6. Erdoğan BM, Uygur F, Meşe B, Tandoğan A, Hedbe L, Serçelik A, et al. Otuz beş yaş ve üzeri hastalarda atriyal septal defekt cerrahisi. Turk Göğüs Kalp Damar 2006;14:205-7.
Ayrıca protez yerleştirilmesi sırasında yapılan insizyonun tercih edilmesinin hastada ek kozmetik probleme sebep olmayacağı düşünülmüştür. Hastada meme protezinin zarar görmesini engellemek adına sağ anterior torakotomi tercih edilmiştir. Cerrahi sahada önümüze gelen protez plastik ve rekonstrüktif cerrahi tarafından dikkatli bir şekilde çıkarılmış, temiz saklanmış ve toraks boşluğu kapatıldıktan sonra diğer meme ile simetrik olacak şekilde yine aynı yerine uygun şekilde yerleştirilmiştir.

Sonuç olarak, her ne kadar tek vaka ile deneyimimiz olsa da silikon meme protezinin özellikle sağ anterolateral torakotomi ile ASD tamirine kontraendike olmadığını tecrübe ettik. Rekonstrüktif meme cerrahisi için yapılan insizyonun kardiak defekt tamiri için de kullanımı nispeten hem kolay ve konforlu cerrahi sağlamış, hem de başarılı kozmetik sonuç elde edilmesine yardımcı olmuştur.

7. van de Woestijne PC, Oei FBS, Bogers AJJC. Minimally invasive atrial septal defect closure. Multimed Man Cardiothorac Surg 2014;2014:mmu002. [CrossRef]

8. Senay S, Gullu AU, Kocyigit M, Degirmencioglu A, Karabulut H, Alhan C. Robotic atrial septal defect closure. Multimed Man Cardiothorac Surg 2014;2014:mmu014. [CrossRef]

9. Xiao C, Gao C, Yang M, Wang G, Wu Y, Wang J, et al. Totally robotic atrial septal defect closure:7-year single-institution experience and follow-up. Interact Cardiovasc Thorac Surg 2014;19:933-7. [CrossRef]

10. Jung JC, Kim KH. Minimally Invasive Cardiac Surgery versus Conventional Median Sternotomy for Atrial Septal Defect Closure. Korean J Thorac Cardiovasc Surg 2016;49:421-6. [CrossRef]

11. Xu M, Zhu S, Wang $X$, Huang $H$, Zhao J. Two Different Minimally Invasive Techniques for Female Patients with Atrial Septal Defects: Totally Thoracoscopic Technique and Right Anterolateral Thoracotomy Technique. Ann Thorac Cardiovasc Surg 2015;21:45965. [CrossRef]

12. Qiao Y, An G, Chen G, Zheng S, Ni L, Wang W, Ma L. Minimally invasive video-assisted double-valve replacement through right anterolateral Minithoracotomy. Heart Lung Circ 2014;23:847-51. [CrossRef] 